\title{
Temperature-Dependent Generalized Planar Fault Energy and Twinnability of Mg Microalloyed with Er, Ho, Dy, Tb, and Gd: First-Principles Study
}

\author{
Lili Liu, ${ }^{1,2}$ Yelu He, ${ }^{1}$ Dingxing Liu, ${ }^{1}$ Xiaozhi Wu, ${ }^{2,3}$ and Rui Wang ${ }^{2}$ \\ ${ }^{1}$ Department of Physics, Chongqing Three Gorges University, Chongqing 404100, China \\ ${ }^{2}$ Institute for Structure and Function, Chongqing University, Chongqing 401331, China \\ ${ }^{3}$ College of Materials Science and Engineering, Chongqing University, Chongqing 400044, China \\ Correspondence should be addressed to Xiaozhi Wu; xiaozhiwu@cqu.edu.cn
}

Received 22 June 2016; Revised 30 September 2016; Accepted 11 October 2016

Academic Editor: Jinghuai Zhang

Copyright ( 2016 Lili Liu et al. This is an open access article distributed under the Creative Commons Attribution License, which permits unrestricted use, distribution, and reproduction in any medium, provided the original work is properly cited.

\begin{abstract}
The generalized planar fault energies, Rice criterion ductility, and twinnability of pure $\mathrm{Mg}$ and $\mathrm{Mg}-\mathrm{RE}$ ( $\mathrm{RE}=\mathrm{Er}, \mathrm{Ho}, \mathrm{Dy}$, Tb, and Gd) alloys at different temperature have been investigated using density functional theory. It is shown that all the fault energies and twinnability in the same materials decrease with increasing temperature. However, the ductility has the opposite change trend. On the other hand, alloying rare earth elements will generally decrease the fault energies and increase the ductility and twinnability of $\mathrm{Mg}$ at different temperature. It is interesting to note that alloying larger atomic radius will enhance the ductility of $\mathrm{Mg}$ more easily and alloying smaller radius will make twinning tendency of $\mathrm{Mg}$ more easily. Finally, the electron structure further reveals the underlying mechanisms for the reduction of fault energies with the addition of rare earth elements.
\end{abstract}

\section{Introduction}

Magnesium alloys have become increasingly attractive in the fields of microelectronics, aerospace, and automotive industries during the past two decades due to light weight and high specific stiffness [1]. However, the potential use of magnesium in wrought forms, such as sheets and extrusions, is quite limited because in hcp magnesium a sufficient number of independent slip systems are in general not readily available. As a result, magnesium's poor ductility is most commonly rationalized in terms of its possession of only one close-packed plane called basal plane. Recently, introducing nanoscale twins has been proved to be useful for enhancing the ductility and fracture toughness of metals. Therefore, activation of deformation twinning plays an important role in the plastic deformation of $\mathrm{Mg}$ alloys [2,3]. Deformation twinning can be considered to be a result of the fact that partial dislocations glide on successive slip planes. The intrinsic stacking fault energy has been traditionally used to describe the ease with which a metal plastically deforms by twinning in competing with dislocation-mediated slip.
However, the deformation mechanism in metals cannot be explained by means of the absolute value of intrinsic stacking fault energy as described by the molecular dynamics (MD) simulations [4-7]. Furthermore, MD simulations $[4,5]$ and mechanical models [8] reveal that generalized planar fault energy (GPFE) curve plays a critical role in the relevant deformation mechanism, especially the competition between twinning partial nucleation and trailing partial nucleation.

Tadmor and Bernstein have shown that the possibilities of mechanical twinning and dislocation-mediated slip in facecentered-cubic $(\mathrm{fcc})$ metals depend significantly on the three typical energies: intrinsic stacking fault energy $\left(\gamma_{\mathrm{sf}}\right)$, unstable stacking fault energy $\left(\gamma_{\mathrm{us}}\right)$, and unstable twinning energy $\left(\gamma_{\mathrm{ut}}\right)[6,7,9-11]$. In general, the three typical energies can be modified by addition of alloying atoms because alloying atoms could disturb the local environment of matrix atoms such as strain field and charge density [12-16]. For example, Han et al. [17] have examined alloying effects due to Li and $\mathrm{Al}$ in terms of generalized stacking fault energies associated with basal planes of $\mathrm{Mg}$; their results show that Li alloying can facilitate dislocation-mediated processes while $\mathrm{Al}$ alloying 
shows an opposite trend. Muzyk et al. [18] calculated the generalized stacking fault energies of Mg-based systems alloyed with $\mathrm{Ag}, \mathrm{Al}, \mathrm{Cu}, \mathrm{Fe}, \mathrm{Li}, \mathrm{Mn}, \mathrm{Ni}, \mathrm{Pb}, \mathrm{Sn}, \mathrm{Ti}, \mathrm{Y}, \mathrm{Zn}$, and $\mathrm{Zr}$; they indicate that alloying with $\mathrm{Y}$ is expected to increase the tendency for mechanical twinning. Kwasniak et al. [19] investigated the deformation tendency of pure $\alpha$-Ti and $\alpha$ Ti alloys with $\mathrm{C}, \mathrm{H}, \mathrm{O}$, and $\mathrm{N}$ additions; their results suggest that $\mathrm{H}$ addition decreases and $\mathrm{C}$ increases twin generation comparing with pure $\alpha$-Ti. Shang et al. $[20,21]$ have studied the twinnability of dilute $\mathrm{Mg}$-based alloys $\mathrm{Mg}_{95} \mathrm{X}(\mathrm{X}=\mathrm{Al}, \mathrm{Ca}$, $\mathrm{Cu}, \mathrm{La}, \mathrm{Li}, \mathrm{Mn}, \mathrm{Sc}, \mathrm{Si}, \mathrm{Sn}, \mathrm{Sr}, \mathrm{Ti}, \mathrm{Y}, \mathrm{Zn}$, and Zr) in terms of firstprinciples calculations; they find that alloying elements $\mathrm{Sr}$ and La increase greatly the twinning propensity of $\mathrm{Mg}$, while $\mathrm{Mn}$, $\mathrm{Ti}$, and $\mathrm{Zr}$ show opposite trends.

Obviously, all the above theoretical investigations about the effects of solute atoms on twinnability of $\mathrm{Mg}$ alloys are confined at $0 \mathrm{~K}$. There is lack of investigation of temperature effects on the twinnability and other mechanical properties of pure $\mathrm{Mg}$ and $\mathrm{Mg}$ alloys [22, 23]. In practice, useful improvements in ductility are seen with elevated temperature, solute additions, and finer sizes [24]. In this paper, the temperature effects on the GPFEs and twinnability of pure $\mathrm{Mg}$ have been studied systematically using a first-principles quasiharmonic approach. Recently, the rare earth metals (RE) and transition metals as the alloying elements are widely used in the $\mathrm{Mg}$ alloys. The rare earth elements especially are a class of special elements which are known to be of major significance for improving the mechanical properties such as ductility, creep resistance, and casting characteristics [25-30]. For example, Gao et al. [26] investigated the effects of rare earth elements Gd and Y on the solid solution strengthening of $\mathrm{Mg}$ alloys by using both the hardness and the tensile tests; they found that solid solution strengthening by Gd and $\mathrm{Y}$ is much higher than the effect of $\mathrm{Al}$ and $\mathrm{Zn}$. Zhang et al. [30] studied systematically the effects of $\mathrm{RE}(\mathrm{RE}=\mathrm{Pr}, \mathrm{Nd}, \mathrm{Gd}$, $\mathrm{Tb}$, and Dy) solute atoms on the stacking faults of $\mathrm{Mg}$ solid solutions using density functional theory; they found that the ductility of $\mathrm{Mg}$ is improved by the addition of RE atoms. Zhang et al. [31] employed a series of supercells to calculate the stable fault energies of basal stacking faults $\mathbf{I}_{1}$ in various categories of $\mathrm{Mg}$-based binary alloys; their results showed that the rare earth elements Er, Ho, Dy, Tb, and Gd decrease the stacking fault energy and are of great significance and effectiveness for improvement of the mechanical behaviors of $\mathrm{Mg}$. Therefore, the GPFEs of Mg microalloyed with Er, Ho, $\mathrm{Dy}, \mathrm{Tb}$, and $\mathrm{Gd}$ are also investigated.

\section{Computational Method}

2.1. Details of First-Principles Calculations. The ab initio calculations are based on density functional theory (DFT) as implemented in the Vienna ab initio simulation package (VASP) code developed at the Institut für Materialphysik of Universität Wien [33-35]. The ion-electron interaction is described by the projector augmented wave (PAW) method $[36,37]$ and the exchange-correlation functional is described by the Perdew-Burke-Ernzerhof (PBE) [38, 39] generalized gradient approximation (GGA). The cut-off energy of plane wave is chosen to be $500 \mathrm{eV}$ for all the calculations. The recommended electron configuration by VASP is employed for each element in the present work, such as 14 electrons $\left(4 \mathrm{f}^{12} 6 \mathrm{~s}^{2}\right)$ used for the valence of Er, $13\left(4 \mathrm{f}^{11} 6 \mathrm{~s}^{2}\right)$ for Ho, 12 $\left(4 \mathrm{f}^{10} 6 \mathrm{~s}^{2}\right)$ for Dy, $11\left(4 \mathrm{f}^{9} 6 \mathrm{~s}^{2}\right)$ for $\mathrm{Tb}, 10\left(4 \mathrm{f}^{7} 5 \mathrm{~d}^{1} 6 \mathrm{~s}^{2}\right)$ for $\mathrm{Gd}$, and $8\left(2 \mathrm{p}^{6} 3 \mathrm{~s}^{2}\right)$ for $\mathrm{Mg}$. Note that semicore $\mathrm{p}$ states are treated as valence electrons for $\mathrm{Mg}$. The $\gamma$-centered Monkhorst-Pack scheme [40] is performed to generate a uniform grid of $k$ points along the three axes in reciprocal space. A $21 \times 21 \times 21$ sampling grid is used to optimize the lattice constants of the unit cell of $\mathrm{Mg}$. The optimized lattice parameters $c / a=$ 1.625 with $a=3.195 \AA$ without considering zero-point vibrational energy in this work are in excellent agreement with experimental values $(c / a=1.624$ with $a=3.209 \AA)$ [41]. In calculation of generalized planar energies of $\mathrm{Mg}-\mathrm{RE}$ alloys at different temperature, periodic supercell of $3 \times 3$ unit cells with 12 layers is used. An $\sim 15 \AA$ vacuum region is included along the cell's long $z$-axis to avoid interactions with periodic images [42]. For this periodic supercell, Brillouin zone sampling is performed using $9 \times 9 \times 2$ special $k$ points mesh. The total energy calculation is performed using linear tetrahedron method with Blöchl et al. correction [43]. The energy convergence criterion of the electronic self-consistency is chosen as $10^{-6} \mathrm{eV}$, while the HellmannFeynman force on all atomic sites is less than $10^{-4} \mathrm{eV} / \AA$ for all calculations. All calculations are performed with the PREC = accurate in INCAR. In order to investigate the effect of spin polarization on the generalized planar energies of $\mathrm{Mg}$ RE alloys, we have also compared the results obtained from the spin-polarized $\gamma_{\text {sf }}$ and the nonpolarized one for fixed temperature. For example, we find that $\gamma_{\mathrm{sf}}$ at $0 \mathrm{~K}$ are 17.82 and $17.80 \mathrm{~mJ} / \mathrm{m}^{2}$ for magnetic and nonmagnetic $\mathrm{MgEr}$, respectively; that is to say, the difference between the spin-polarized and the nonpolarized calculations is negligible. Therefore, the temperature-dependent generalized planar energies of pure $\mathrm{Mg}$ and $\mathrm{Mg}$-RE (RE = Er, Ho, Dy, Tb, and Gd) alloys are performed within the nonpolarized calculations in this work.

2.2. Temperature-Dependent Properties. In order to calculate the temperature-dependent generalized planar energies of $\mathrm{Mg}$ and $\mathrm{Mg}$-RE alloys, we need the equilibrium volume $V$ at the given $T$. The Helmholtz free energy $F(V, T)$ at temperature $T$ and constant volume $V$ based on the quasiharmonic approach can be expressed as

$$
F(V, T)=U_{\text {static }}(V)+F_{\mathrm{ph}}(V, T),
$$

where $U_{\text {static }}(V)$ is the static energy obtained from firstprinciples calculations directly and $F_{\mathrm{ph}}(V, T)$ is the phonon free energy arising from the lattice vibrations. Within the quasiharmonic approach,

$$
F_{\mathrm{ph}}(V, T)=\sum_{k}\left[\frac{1}{2} \hbar \omega_{k}+k_{B} T \ln \left(1-e^{-\hbar \omega_{k} / k_{B} T}\right)\right],
$$

where $\hbar$ is the reduced Planck constant, $k_{B}$ is the Boltzmann constant, and $\omega_{k}$ represents an individual phonon frequency. Here, the sum is overall the phonon frequency in the first Brillouin zone. Phonon frequency calculations are performed by the supercell approach with the force constants calculated 
TABLE 1: The total energy $(\mathrm{eV})$ of Mg-RE (RE = Er, Ho, Dy, Tb, and Gd) alloys replacing one atom of Mg in the 4th, 5th, 6th, 7th, 8th, 9th, and 10th layers by a rare earth atom, respectively (see Figure 3(a)).

\begin{tabular}{|c|c|c|c|c|c|c|c|}
\hline Layer & 4 & 5 & 6 & 7 & 8 & 9 & 10 \\
\hline $\mathrm{Mg}+\mathrm{Er}$ & -169.770 & -169.839 & -169.848 & -169.849 & -169.838 & -169.770 & -169.720 \\
\hline $\mathrm{Mg}+\mathrm{Ho}$ & -169.790 & -169.862 & -161.871 & -169.873 & 169.861 & -169.790 & -169.736 \\
\hline $\mathrm{Mg}+\mathrm{Dy}$ & -169.817 & -169.891 & -169.900 & -169.910 & -169.891 & -169.816 & -169.759 \\
\hline $\mathrm{Mg}+\mathrm{Tb}$ & -169.845 & -169.922 & -169.931 & -169.938 & -169.922 & -169.844 & -169.784 \\
\hline $\mathrm{Mg}+\mathrm{Gd}$ & -169.865 & -169.945 & -169.954 & -169.956 & -169.945 & -169.865 & -169.801 \\
\hline
\end{tabular}

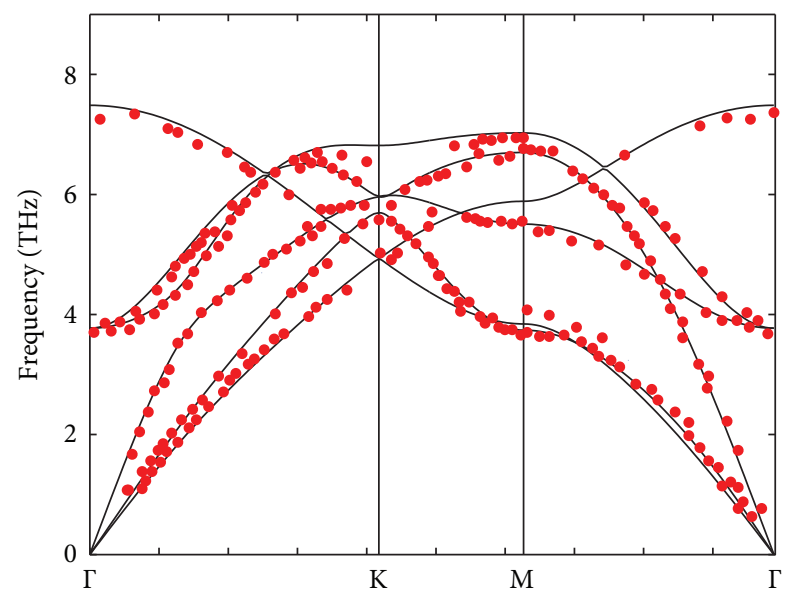

FIGURE 1: Calculated phonon dispersion curves of bulk Mg along high-symmetry directions in the Brillouin zone. The red solid circles show the experimentally measured frequencies [32].

in the density functional perturbation theory implemented in the VASP code [44]. Here, a $4 \times 4 \times 3$ supercell with 96 atoms is employed based on our tests. The forces resulting from displacements of certain atoms in this supercell are calculated by VASP with $5 \times 5 \times 4 k$-points grid meshes. The other settings of VASP calculations are the same as described above. The phonon frequency is obtained by using the PHONOPY [4547] package which can support VASP interface to calculate force constants matrix directly. The phonon dispersion curves for $\mathrm{Mg}$ along high-symmetry directions in the Brillouin zone computed with theoretical equilibrium lattice parameters are plotted in Figure 1. Obviously, the spectra are in agreement with those from the inelastic neutron scattering measurement depicted by red solid circles [32].

Based on (1), the equilibrium volume versus temperature relation $V(T)$ is straightforward. We have calculated the static energy $U_{\text {static }}(V)$ and the phonon free energy $F_{\text {ph }}(V, T)$ at 15 volume points near the theoretical equilibrium volume for $\mathrm{Mg}$. The equilibrium volume $V$ at temperature $T$ is obtained by minimizing Helmholtz free energy with respect to $V$ from fitting to the integral form of the Vinet equation of state (EOS) [48]. Figure 2(a) displays the values of Helmholtz free energy as a function of unit cell volume of $\mathrm{Mg}$ at every $100 \mathrm{~K}$ between 0 and $600 \mathrm{~K}$, and the value depicted by the red circle of every fitted curve is the equilibrium volume at corresponding temperature. It is assumed that the ratio of $c / a$ is 1.625 at different temperature. The thermal expansion is obvious as the equilibrium volume increases (see Figure 2(b)). Because the unit cell of Mg-RE contains 108 atoms, obtaining the phonon dispersion of typical $\mathrm{Mg}$ - RE needs a considerable amount of calculation. And the doping concentration is very low, so we estimate the fact that the five Mg-based alloys have the same equilibrium volumes at different temperatures with $\mathrm{Mg}$.

\section{Results and Discussion}

The radius of $\mathrm{Mg}$ is $1.72 \AA$ and the radii of rare earth metals Er, Ho, Dy, Tb, and Gd are 2.45, 2.47, 2.49, 2.51, and $2.54 \AA$, respectively. Obviously, all the rare earth metal atomic radii are larger than that of $\mathrm{Mg}$. To study the effect of the rare earth metals on the twinnability of Mg-based alloys, the accurate positions of the rare earth metals to the $3 \times 3$ slab geometry with 12 (0001) atomic planes, corresponding to $\sim 0.9$ at. $\%$ concentration of solute ( $\sim 11.1$ at.\% monolayer coverage at the doped plane), are firstly determined with the minimum energy for all the most possible occupation sites. Figure 3(a) displays the perfect atomic configuration of the supercell arranged into a $\mathrm{ABAB}$ sequence with $15 \AA$ vacuum in the direction perpendicular to the slip plane. For the $\mathrm{Mg}$ $\mathrm{RE}$ alloys, one $\mathrm{Mg}$ atom is substituted by a rare earth metal in the 4th, 5th, 6th, 7th, 8th, 9th, and 10th layers, respectively. All the calculated total energies are listed in Table 1. Obviously, we can conclude that the optimum position of the solute atom is in the 7th layer.

The calculated temperature-dependent generalized planar fault energy curves for $\mathrm{Mg}$ are shown in Figure 4. The first half of the generalized planar fault energy curves is evaluated by displacing the upper layers numbered 1-6 with respect to the atomic layers numbered 7-12 over a displacement $a / \sqrt{3}$ and the stacking fault $\mathrm{ABABAB}(\mathrm{C}) \mathrm{ACACA}$ is created (see Figure 3(b)). The second half is then evaluated by successively sliding layers $8-12$ in similar fashion and the deformation twin $\mathrm{ABABAB}(\mathrm{C}) \mathrm{BABAB}$ is generated (see Figure 3(c)). It is well known that deformation twinning in metals and alloys is initiated by preexisting dislocation configurations which dissociate into multilayered stacking fault structures to nucleate a twin. The first and the second maxima in Figure 4 are unstable stacking fault energy $\gamma_{\mathrm{us}}$ and unstable twinning energy $\gamma_{\mathrm{ut}}$, respectively, and the first minimum is the stable stacking fault energy $\gamma_{\mathrm{ss}}$. While $\gamma_{\mathrm{sf}}$ can be measured experimentally, $\gamma_{\mathrm{us}}$ and $\gamma_{\mathrm{ut}}$ are difficult to be obtained from experimental measurements and can be determined only through atomic simulation, which represent the minimum energy barriers for partial dislocation nucleation [49] and microtwin nucleation, respectively. 


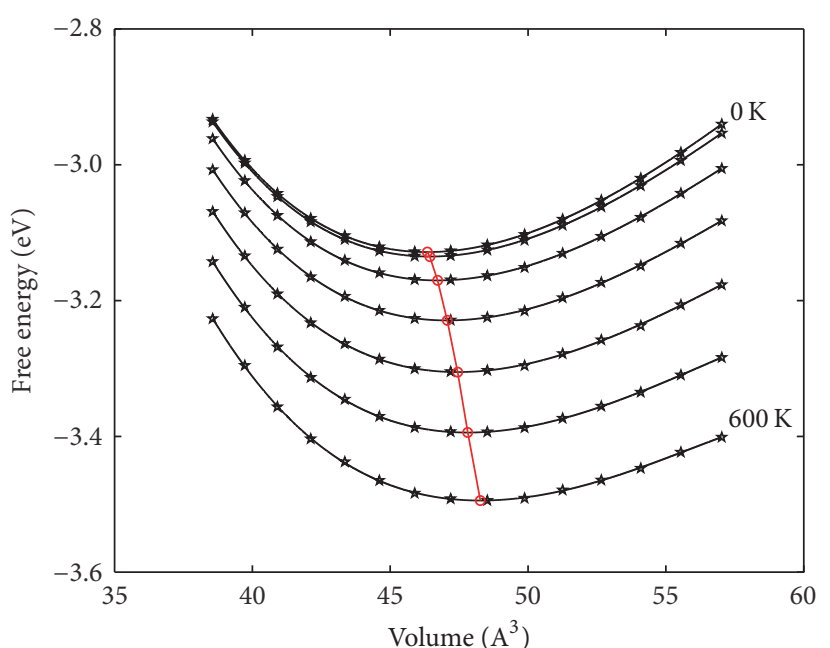

(a)

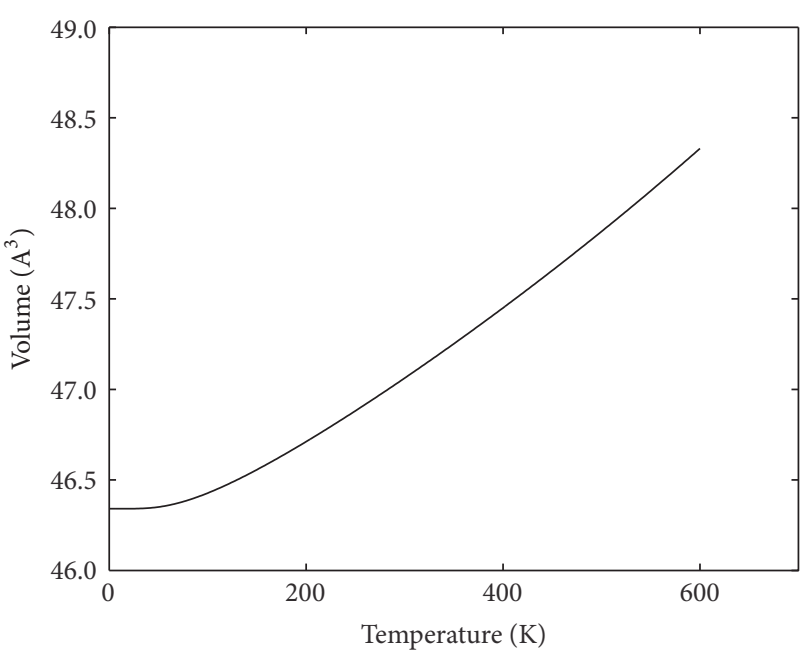

(b)

Figure 2: (a) The values of Helmholtz free energy as a function of unit cell volume of pure $\mathrm{Mg}$ between 0 and $600 \mathrm{~K}$ at every $100 \mathrm{~K}$. The minimum value depicted by red circle of every fitted curve is the equilibrium volume at corresponding temperature. (b) The equilibrium volume of pure $\mathrm{Mg}$ as a function of temperature.

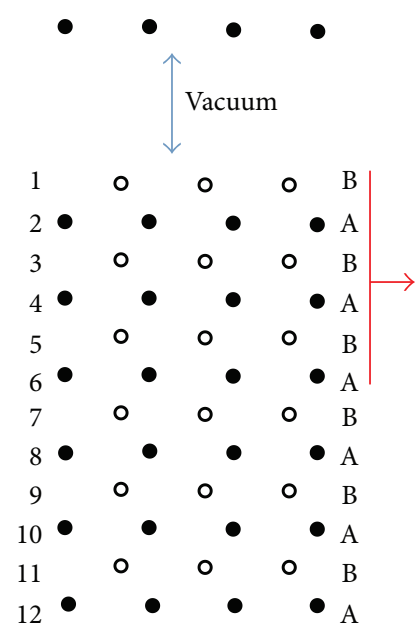

(a) No fault

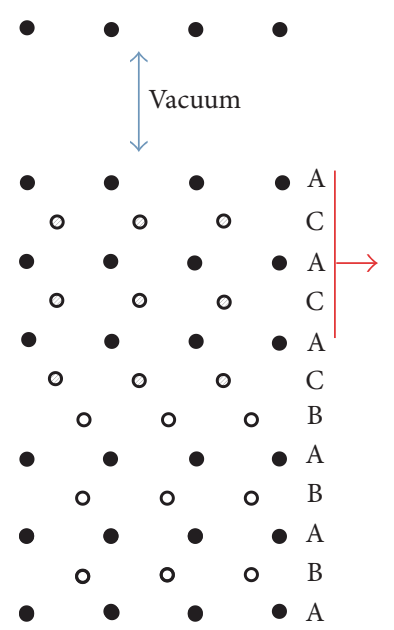

(b) Stacking fault

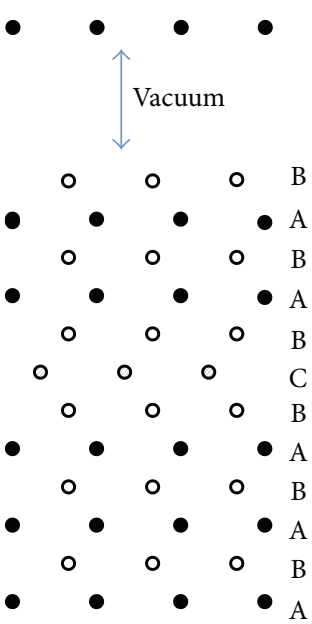

(c) Twinning fault

Figure 3: A schematic representation of the model used in the computations: (a) initial structure, (b) stacking fault structure imposed by sliding layers numbered 1-6 in the upper part, and (c) twinning fault configuration generated by displacing layers 1-5 in similar fashion. All configurations separated from the rest by a $15 \AA$ thick vacuum. For the Mg-RE (RE = Er, Ho, Dy, Tb, and Gd) alloys, one atom of Mg in the seventh layer is replaced by the rare earth element.

All the calculated fault energies $\left(\gamma_{\mathrm{sf}}, \gamma_{\mathrm{us}}\right.$, and $\left.\gamma_{\mathrm{ut}}\right)$ at different temperature for pure $\mathrm{Mg}$ and $\mathrm{Mg}$-based alloys are summarized in Table 2. The present stable stacking fault energy $\left(33.5 \mathrm{~mJ} / \mathrm{m}^{2}\right)$ of $\mathrm{Mg}$ at $0 \mathrm{~K}$ agrees well with other first-principles results $\left(\sim 21-44 \mathrm{~mJ} / \mathrm{m}^{2}\right)$ [50-57]. However, the result $\left(31.1 \mathrm{~mJ} / \mathrm{m}^{2}\right)$ at $300 \mathrm{~K}$ is lower than the scattered experimental values measured at room temperature $\left(<50 \mathrm{~mJ} / \mathrm{m}^{2}\right.$ [58], 74, 102, 125, and $280 \mathrm{~mJ} / \mathrm{m}^{2}$ [59], and $>90 \mathrm{~mJ} / \mathrm{m}^{2}[60]$ ). It is worth mentioning that the existing experimental values of stable stacking fault energy in this paper are not reliable since the experimental measurements are often complex and elusive due to the smaller stable stacking fault energy.
The present results of other generalized planar fault energies of pure $\mathrm{Mg}$ including unstable stacking fault energy $\left(95.8 \mathrm{~mJ} / \mathrm{m}^{2}\right)$ and unstable twinning energy $\left(114.5 \mathrm{~mJ} / \mathrm{m}^{2}\right)$ at $0 \mathrm{~K}$ are in general agreement with previous theoretical values $[18,21,51]$. Therefore, the calculation of this work should be reasonable and reliable. On the other hand the fault energies at finite temperature of pure $\mathrm{Mg}$ and $\mathrm{Mg}$-based alloys are absent both experimentally and theoretically, which are worth verification in the future. From Table 2, it can be seen that all the fault energies of $\mathrm{Mg}$ and $\mathrm{Mg}$-based alloys decrease slightly with increasing temperature, since thermal expansion may soften the stacking fault configuration at high 
TABLE 2: Calculated fault energies $\left(\gamma_{i}, \mathrm{~mJ} \mathrm{~m}^{-2}\right)$, ductility parameter $\left(D=0.3 \gamma_{s} / \gamma_{\mathrm{us}}\right)$, and relative barrier heights $\left(\gamma_{\mathrm{sf}} / \gamma_{\mathrm{us}}, \gamma_{\mathrm{ut}} / \gamma_{\mathrm{us}}\right)$ of Mg and Mg-based alloys in the temperature range $0-600 \mathrm{~K}$ by using the supercell of a $3 \times 3$ slab geometry with 12 atomic planes.

\begin{tabular}{|c|c|c|c|c|c|c|c|}
\hline $\mathrm{T}(\mathrm{K})$ & System & $\gamma_{\mathrm{sf}}$ & $\gamma_{\mathrm{us}}$ & $\gamma_{\mathrm{ut}}$ & $D$ & $\gamma_{\mathrm{sf}} / \gamma_{\mathrm{us}}$ & $\gamma_{\mathrm{ut}} / \gamma_{\mathrm{us}}$ \\
\hline \multirow{6}{*}{0} & $\mathrm{Mg}$ & 33.5 & 95.8 & 114.5 & 1.710 & 0.349 & 1.195 \\
\hline & $\mathrm{Mg}-\mathrm{Er}$ & 17.8 & 94.2 & 108.7 & 1.739 & 0.189 & 1.153 \\
\hline & Mg-Ho & 17.1 & 93.7 & 108.3 & 1.749 & 0.182 & 1.155 \\
\hline & Mg-Dy & 16.3 & 93.2 & 107.8 & 1.758 & 0.175 & 1.156 \\
\hline & $\mathrm{Mg}-\mathrm{Tb}$ & 15.4 & 92.6 & 107.2 & 1.769 & 0.167 & 1.158 \\
\hline & Mg-Gd & 14.4 & 91.9 & 106.5 & 1.783 & 0.157 & 1.159 \\
\hline \multirow{6}{*}{200} & $\mathrm{Mg}$ & 32.3 & 93.4 & 111.7 & 1.752 & 0.346 & 1.196 \\
\hline & $\mathrm{Mg}-\mathrm{Er}$ & 16.5 & 92.3 & 106.5 & 1.775 & 0.179 & 1.154 \\
\hline & Mg-Ho & 16.0 & 91.8 & 106.1 & 1.785 & 0.174 & 1.155 \\
\hline & Mg-Dy & 15.9 & 91.4 & 105.7 & 1.793 & 0.173 & 1.157 \\
\hline & $\mathrm{Mg}-\mathrm{Tb}$ & 15.0 & 90.8 & 105.2 & 1.804 & 0.166 & 1.159 \\
\hline & Mg-Gd & 14.0 & 90.1 & 104.5 & 1.818 & 0.155 & 1.160 \\
\hline \multirow{6}{*}{300} & $\mathrm{Mg}$ & 31.1 & 91.4 & 109.4 & 1.791 & 0.340 & 1.197 \\
\hline & $\mathrm{Mg}-\mathrm{Er}$ & 15.9 & 90.5 & 104.6 & 1.810 & 0.176 & 1.156 \\
\hline & Mg-Ho & 15.6 & 90.1 & 104.3 & 1.818 & 0.173 & 1.158 \\
\hline & Mg-Dy & 15.5 & 89.6 & 103.9 & 1.829 & 0.172 & 1.159 \\
\hline & $\mathrm{Mg}-\mathrm{Tb}$ & 14.6 & 89.1 & 103.4 & 1.839 & 0.165 & 1.160 \\
\hline & Mg-Gd & 13.7 & 88.5 & 102.7 & 1.851 & 0.154 & 1.161 \\
\hline \multirow{6}{*}{400} & $\mathrm{Mg}$ & 29.7 & 89.1 & 106.7 & 1.837 & 0.333 & 1.198 \\
\hline & Mg-Er & 15.2 & 88.4 & 102.4 & 1.853 & 0.171 & 1.158 \\
\hline & Mg-Ho & 14.8 & 88.1 & 102.1 & 1.860 & 0.168 & 1.159 \\
\hline & Mg-Dy & 14.3 & 87.7 & 101.8 & 1.868 & 0.163 & 1.160 \\
\hline & $\mathrm{Mg}-\mathrm{Tb}$ & 14.1 & 87.2 & 101.3 & 1.879 & 0.162 & 1.161 \\
\hline & Mg-Gd & 13.2 & 86.7 & 100.8 & 1.890 & 0.152 & 1.162 \\
\hline \multirow{6}{*}{600} & $\mathrm{Mg}$ & 26.6 & 84.0 & 100.7 & 1.946 & 0.316 & 1.199 \\
\hline & $\mathrm{Mg}-\mathrm{Er}$ & 13.6 & 83.9 & 97.4 & 1.953 & 0.162 & 1.160 \\
\hline & Mg-Ho & 13.3 & 83.7 & 97.2 & 1.958 & 0.159 & 1.161 \\
\hline & Mg-Dy & 12.7 & 83.3 & 96.9 & 1.967 & 0.153 & 1.164 \\
\hline & $\mathrm{Mg}-\mathrm{Tb}$ & 12.2 & 82.9 & 96.6 & 1.976 & 0.147 & 1.165 \\
\hline & $\mathrm{Mg}-\mathrm{Gd}$ & 11.5 & 82.4 & 96.1 & 1.988 & 0.139 & 1.166 \\
\hline
\end{tabular}

temperature. Note that the decrease of fault energies of fcc metals with increasing temperature is predicted previously [20]. Besides, it is interesting to find that doping rare earth metals at this concentration will generally decrease the fault energies at different temperature. Moreover, the reduction of $\gamma_{\mathrm{sf}}$ is more obvious than that of $\gamma_{\mathrm{us}}$ and $\gamma_{\mathrm{ut}}$. For example, the $\gamma_{\text {sf }}$ value of $\mathrm{Mg}$ at $0 \mathrm{~K}$ is $33.5 \mathrm{~mJ} / \mathrm{m}^{2}$, while in the alloys $\gamma_{\text {sf }}$ ranges from 14.4 to $17.8 \mathrm{~mJ} / \mathrm{m}^{2}$. The size of $\gamma_{\mathrm{sf}}$ is decreased by nearly half with the alloying atoms at different temperature. On the other hand, with the increase of the atomic radius of rare earth metals, the reduction of fault energies for $\mathrm{Mg}-\mathrm{RE}$ alloys becomes strong.

To examine how alloying and temperature alter the ductility of pure Mg we employ Rice criterion [49]. Rice has shown that the conditions for both brittle fracture and the nucleation and motion of dislocations can be simply measured from the ductility parameter $D=0.3 \gamma_{s} / \gamma_{\text {us }}$ [49], where $\gamma_{s}$ is the (0001) surface energy of pure $\mathrm{Mg}$ or the appropriate $\mathrm{Mg}$ alloy, including the effects of surface segregation. If $\gamma_{s}$ is small relative to $\gamma_{\mathrm{us}}$ then under applied stress the metal will tend to form surface, that is, crack, rather than shearing by dislocation-mediated slip. The $\gamma_{s}$ value of pure $\mathrm{Mg}$ ranges from $546.17 \mathrm{~mJ} / \mathrm{m}^{2}$ to $548.47 \mathrm{~mJ} / \mathrm{m}^{2}$ in the temperature range $0-600 \mathrm{~K}$ and the increment is about $0.4 \%$. Since the temperature and the rare earth metals have little influence on $\gamma_{s}$ value of pure $\mathrm{Mg}$, we employ the $\gamma_{s}$ value $\left(546.17 \mathrm{~mJ} / \mathrm{m}^{2}\right)$ at $0 \mathrm{~K}$ to calculate the ductility parameters for pure $\mathrm{Mg}$ and $\mathrm{Mg}$-based alloys at different temperature. All the ductility parameters $D$ for pure $\mathrm{Mg}$ and $\mathrm{Mg}$-based alloys at different temperature are summarized in Table 2. Note that all the values are larger than 1, so $\mathrm{Mg}$ and $\mathrm{Mg}$-based alloys are considered to be ductile at different temperature. The smaller $\gamma_{\text {us }}$ of Mg-based alloys corresponds to the larger value of ductility parameter, which demonstrates that the crystals tend to nucleate dislocations rather than shear so as to form surfaces, so the ductility would be improved by the rare earth metals. It should be noted that the rare earth elements is of great significance and effectiveness for improvement of the mechanical properties such as ductility, creep resistance, and casting characteristics [25-30]. Furthermore, the ductility parameter increases with 


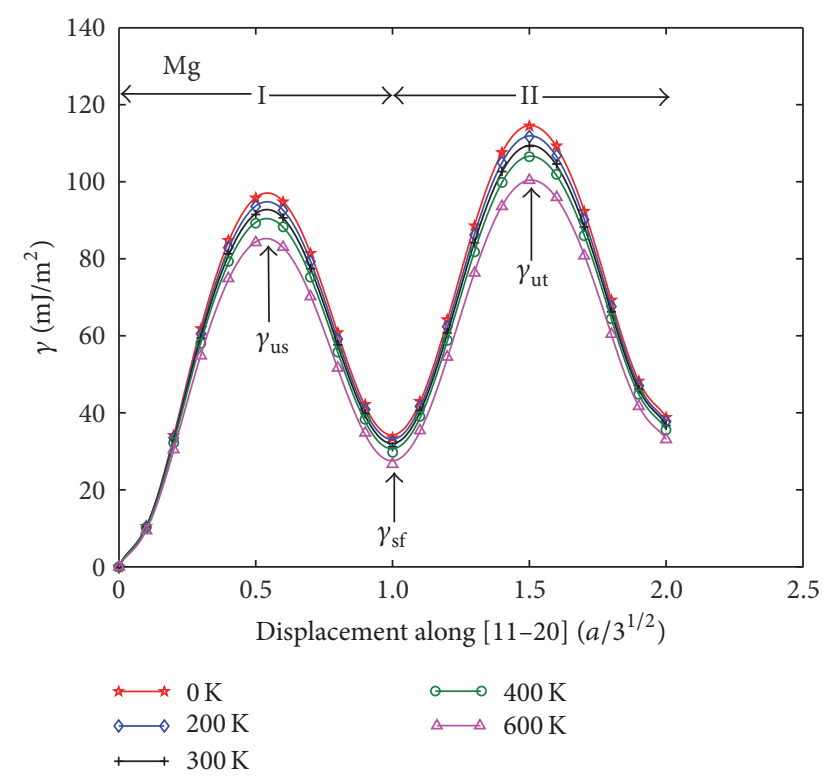

FIGURE 4: The generalized planar fault energy curves of $\mathrm{Mg}$ at different temperature. The discrete points denote the values of firstprinciples calculations and the solid lines indicate the results from polynomial fitting.

increasing the atomic radius of rare earth metals, which demonstrates that alloying larger atomic radius of rare earth metals will enhance the ductility of $\mathrm{Mg}$ more easily. Besides, the ductility of pure $\mathrm{Mg}$ and $\mathrm{Mg}$-based alloys increases with increasing temperature, and it results from the fact that $\gamma_{\mathrm{us}}$ decrease and $\gamma_{s}$ almost unchange with increasing temperature in the same materials.

The fault energies $\left(\gamma_{\mathrm{sf}}, \gamma_{\mathrm{us}}\right.$, and $\left.\gamma_{\mathrm{ut}}\right)$ play a critical role in the activation of the extended partials and deformation twinning. The deformation mechanism and twinning tendency of the material are expected to depend on the value of $\gamma_{\mathrm{sf}} / \gamma_{\mathrm{us}}$ and $\gamma_{\mathrm{ut}} / \gamma_{\mathrm{us}}[4,6,19]$. Values of these parameters close to 1.0 imply that deformation by full dislocation is preferred. Decrease of these parameters favors deformation by partial dislocation and twinning. All the values of these parameters are listed in Table 2. For all additions $\gamma_{\mathrm{sf}} / \gamma_{\mathrm{us}}$ and $\gamma_{\mathrm{ut}} / \gamma_{\mathrm{us}}$ are smaller than that for pure $\mathrm{Mg}$ at different temperature. The results obtained in this work indicate that alloying rare earth metals at this concentration will make deformation by partial dislocations and twinning more easily. In fact, sorting the interstitials investigated here according to their decreasing $\gamma_{\text {sf }} / \gamma_{\text {us }}$ context, we obtain the ranking at different temperature: $\mathrm{Er}<\mathrm{Ho}<\mathrm{Dy}<\mathrm{Tb}<\mathrm{Gd}$, which demonstrates that alloying larger atomic radius of rare earth metals will make deformation of partial dislocation more easily. The same elements can be ordered in terms of their decreasing $\gamma_{\mathrm{ut}} / \gamma_{\mathrm{us}}$ at different temperature in the sequence $\mathrm{Gd}<\mathrm{Tb}<$ $\mathrm{Dy}<\mathrm{Ho}<\mathrm{Er}$, which indicate that alloying smaller radius of rare earth metals will make twinning tendency more easily. In a word, the deformation mechanism and twinning tendency have the opposite change trend with the radius of rare earth metals at different temperature. On the other hand, temperature is beneficial to promote the dissociation of dislocation into partials more easily since $\gamma_{\mathrm{sf}} / \gamma_{\mathrm{us}}$ of $\mathrm{Mg}$ and $\mathrm{Mg}$-based alloys decrease with increasing temperature. However, it can be seen from Table 2 that the $\gamma_{\text {ut }} / \gamma_{\text {us }}$ values of $\mathrm{Mg}$ and $\mathrm{Mg}$ based alloys increase slowly with increasing temperature, so it can be concluded that the twinnability decreases slowly with increasing temperature, which is in accordance with the experimental phenomenon that low temperature can promote deformation twinning [61].

In general, variations of the fault energies of $\mathrm{Mg}$ and $\mathrm{Mg}$ based alloys can be analyzed qualitatively in terms of the charge density distributions. Owing to the similar influence of rare earth elements on the fault energies, only Dy is taken as an example to be described in detail. Figure 5 illus-

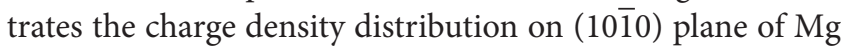
and $\mathrm{Mg}-\mathrm{Dy}$ alloy for four rigid shear configurations. From Figure 5(a), it can be seen that a high charge density area marked by red boat-like area is adjacent to each $\mathrm{Mg}$ atom at the nonfaulted structure (P). During shearing, Mg expels surrounding electrons away from itself and the charge density around it will thus be decreased. Since more electrons have to be redistributed during the formation process of the unstable stacking fault structure (USF), the total energy is increased. With continuous shear, the high charge density area around $\mathrm{Mg}$ is further reduced and tries to reach a new stable distribution. Finally, a new and relatively stable stacking fault configuration (SF) is formed. Therefore, the stable stacking fault energy is lower than unstable stacking fault energy. At the unstable twinning (UT) configuration, the high density area adjacent to $\mathrm{Mg}$ atom on the near fault plane (L8) becomes smaller and the charge redistribution is most serious. As a result, the unstable twinning energy is higher than the unstable stacking fault energy and the stable stacking fault energy. Figure 5(b) shows the similar situation of charge density distribution of Mg-Dy alloy during the formation process of twinning fault configuration. There is a progressive increase in the valence charge in the vicinity of Dy atom relative to $\mathrm{Mg}$, showing that substitutional rare earth element increases charge at the fault plane. Owing to the enhanced charge density around Dy element, the interaction between atomic layers near the fault plane is stronger during the entire shear process, so all the fault energies are lower in comparison with the case of pure $\mathrm{Mg}$. It should be noted that the charge transfer process is in accordance with Zhang et al. results [30].

\section{Conclusions}

In summary, we have employed first-principles approach to calculate the generalized planar fault energies for $\mathrm{Mg}$ and $\mathrm{Mg}$ $\mathrm{RE}(\mathrm{RE}=\mathrm{Er}, \mathrm{Ho}, \mathrm{Dy}, \mathrm{Tb}$, and Gd) alloys as a function of temperature. The results indicate that all the fault energies decrease with increasing temperature and alloying rare earth elements will generally lower the fault energies of $\mathrm{Mg}$ at different temperature. Based on the calculated fault energies, the brittle-ductile behavior and the deformation twinning of $\mathrm{Mg}$ and $\mathrm{Mg}$-based alloys have been investigated. It is found that the ductility increases and the twinnability decreases with increasing temperature for $\mathrm{Mg}$ and $\mathrm{Mg}$-based alloys. Furthermore, alloying rare earth elements will generally increase the ductile and twinnability of $\mathrm{Mg}$ at different temperature. It 

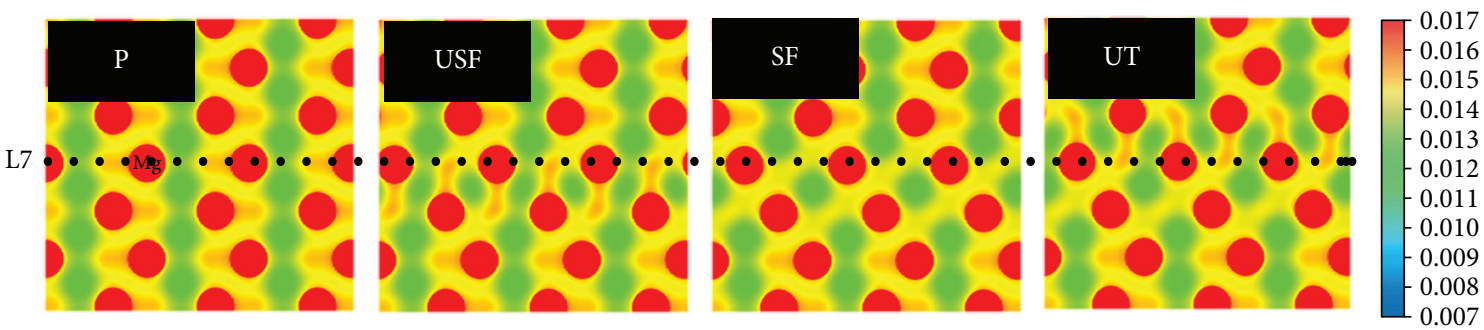

(a)
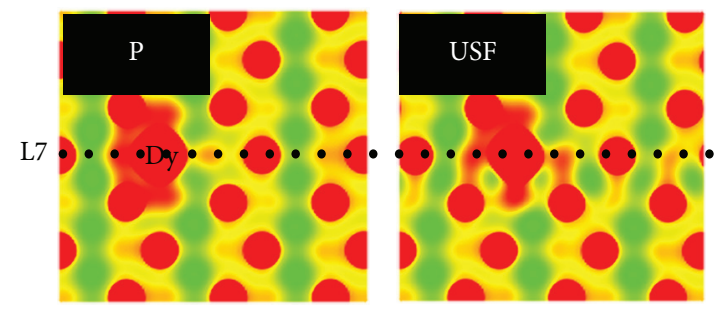

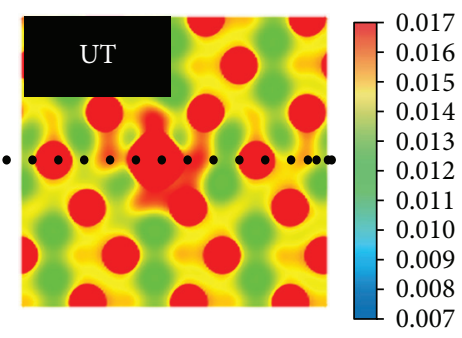

(b)

FIGURE 5: The charge densities contour plots of perfect (P) configuration, unstable stacking fault (USF) configuration, stacking fault (SF) configuration, and unstable twinning (UT) configuration for pure $\mathrm{Mg}$ (a) and Mg-Dy solid solution (b) on the (1010) plane. The dots mark the fault layer (L7).

is interesting to note that alloying larger atomic radius will enhance the ductility of $\mathrm{Mg}$ more easily and alloying smaller radius will make twinning tendency of $\mathrm{Mg}$ more easily. Finally, the electron structure further reveals the underlying mechanisms for the reduction of fault energies with the addition of rare earth elements.

\section{Competing Interests}

The authors declare that they have no competing interests.

\section{Acknowledgments}

This work is supported by the Natural Science Foundation of China (11104361) and Project supported by program for Innovation Team Building at institutions of higher education in Chongqing (CXTDX201601034) and Project supported by the Fundamental Research Funds for the Central Universities (CDJXY300003).

\section{References}

[1] K. U. Kainer, Magnesium-Alloys and Technologies, Wiley-VCH, Weinheim, Germany, 2003.

[2] A. H. Feng and Z. Y. Ma, "Microstructural evolution of cast Mg$\mathrm{Al}-\mathrm{Zn}$ during friction stir processing and subsequent aging," Acta Materialia, vol. 57, no. 14, pp. 4248-4260, 2009.

[3] L. Wu, S. R. Agnew, D. W. Brown et al., "Internal stress relaxation and load redistribution during the twinning-detwinningdominated cyclic deformation of a wrought magnesium alloy, ZK60A," Acta Materialia, vol. 56, no. 14, pp. 3699-3707, 2008.

[4] H. Van Swygenhoven, P. M. Derlet, and A. G. Frøseth, "Stacking fault energies and slip in nanocrystalline metals," Nature Materials, vol. 3, no. 6, pp. 399-403, 2004.
[5] A. G. Frøseth, P. M. Derlet, and H. V. Swygenhoven, "Grownin twin boundaries affecting deformation mechanisms in ncmetals," Applied Physics Letters, vol. 85, no. 24, pp. 5863-5865, 2004.

[6] N. Bernstein and E. Tadmor, "Tight-binding calculations of stacking energies and twinnability in fcc metals," Physical Review B, vol. 69, no. 9, Article ID 094116, 2004.

[7] E. B. Tadmor and N. Bernstein, "A first-principles measure for the twinnability of FCC metals," Journal of the Mechanics and Physics of Solids, vol. 52, no. 11, pp. 2507-2519, 2004.

[8] R. J. Asaro and S. Suresh, "Mechanistic models for the activation volume and rate sensitivity in metals with nanocrystalline grains and nano-scale twins," Acta Materialia, vol. 53, no. 12, pp. 3369-3382, 2005.

[9] D. J. Siegel, "Generalized stacking fault energies, ductilities, and twinnabilities of $\mathrm{Ni}$ and selected Ni alloys," Applied Physics Letters, vol. 87, no. 12, Article ID 121901, 2005.

[10] S. Kibey, J. B. Liu, D. D. Johnson, and H. Sehitoglu, "Generalized planar fault energies and twinning in $\mathrm{Cu}-\mathrm{Al}$ alloys," Applied Physics Letters, vol. 89, no. 19, Article ID 191911, 2006.

[11] S. Kibey, J. B. Liu, D. D. Johnson, and H. Sehitoglu, "Energy pathways and directionality in deformation twinning," Applied Physics Letters, vol. 91, no. 18, Article ID 181916, 2007.

[12] A. Datta, U. Ramamurty, S. Ranganathan, and U. V. Waghmare, "Crystal structures of a Mg-Zn-Y alloy: a first-principles study," Computational Materials Science, vol. 37, no. 1-2, pp. 69-73, 2006.

[13] S. Sandlöbes, M. Friák, S. Zaefferer et al., "The relation between ductility and stacking fault energies in $\mathrm{Mg}$ and $\mathrm{Mg}$-Y alloys," Acta Materialia, vol. 60, no. 6-7, pp. 3011-3021, 2012.

[14] Z. Pei, L.-F. Zhu, M. Friák et al., "Ab initio and atomistic study of generalized stacking fault energies in Mg and Mg-Y alloys," New Journal of Physics, vol. 15, no. 4, Article ID 043020, 2013. 
[15] T. W. Fan, L. T. Wei, B. Y. Tang et al., "Effect of temperatureinduced solute distribution on stacking fault energy in $\mathrm{Mg}$ $\mathrm{X}(\mathrm{X}=\mathrm{Li}, \mathrm{Cu}, \mathrm{Zn}, \mathrm{Al}, \mathrm{Y}$ and $\mathrm{Zr})$ solid solution: a first-principles study," Philosophical Magazine, vol. 94, no. 14, pp. 1578-1587, 2014.

[16] W. Li, S. Lu, Q. Hu, S. K. Kwon, B. Johansson, and L. Vitos, “Generalized stacking fault energies of alloys," Journal of Physics: Condensed Matter, vol. 26, no. 26, Article ID 265005, 2014.

[17] J. Han, X. M. Su, Z.-H. Jin, and Y. T. Zhu, "Basal-plane stackingfault energies of Mg: a first-principles study of Li- and Alalloying effects," Scripta Materialia, vol. 64, no. 8, pp. 693-696, 2011.

[18] M. Muzyk, Z. Pakiela, and K. J. Kurzydlowski, "Generalized stacking fault energy in magnesium alloys: density functional theory calculations," Scripta Materialia, vol. 66, no. 5, pp. 219222, 2012.

[19] P. Kwasniak, M. Muzyk, H. Garbacz, and K. J. Kurzydlowski, "Influence of $\mathrm{C}, \mathrm{H}, \mathrm{N}$, and $\mathrm{O}$ interstitial atoms on deformation mechanism in titanium-first principles calculations of generalized stacking fault energy," Materials Letters, vol. 94, pp. 9294, 2013.

[20] S. L. Shang, W. Y. Wang, Y. Wang et al., "Temperature-dependent ideal strength and stacking fault energy of fcc Ni: a firstprinciples study of shear deformation," Journal of Physics: Condensed Matter, vol. 24, no. 15, Article ID 155402, 2012.

[21] S. L. Shang, W. Y. Wang, B. C. Zhou et al., "Generalized stacking fault energy, ideal strength and twinnability of dilute Mg-based alloys: a first-principles study of shear deformation," Acta Materialia, vol. 67, pp. 168-180, 2014.

[22] S. Iikubo, K. Matsuda, and H. Ohtani, "Phase stability of longperiod stacking structures in Mg-Y-Zn: a first-principles study," Physical Review B, vol. 86, no. 5, Article ID 054105, 2012.

[23] P. A. T. Olsson, "First principles investigation of the finite temperature dependence of the elastic constants of zirconium, magnesium and gold," Computational Materials Science, vol. 99, pp. 361-372, 2015.

[24] M. M. Avedesian and H. Baker, "Magnesium and magnesium alloys," in ASM Speciality Handbook, ASM International, Metals Park, Ohio, USA, 1999.

[25] N. Birbilis, M. K. Cavanaugh, A. D. Sudholz, S. M. Zhu, M. A. Easton, and M. A. Gibson, "A combined neural network and mechanistic approach for the prediction of corrosion rate and yield strength of magnesium-rare earth alloys," Corrosion Science, vol. 53, no. 1, pp. 168-176, 2011.

[26] L. Gao, R. S. Chen, and E. H. Han, "Effects of rare-earth elements $\mathrm{Gd}$ and $\mathrm{Y}$ on the solid solution strengthening of $\mathrm{Mg}$ alloys," Journal of Alloys and Compounds, vol. 481, no. 1-2, pp. 379-384, 2009.

[27] S. Sandlöbes, S. Zaefferer, I. Schestakow, S. Yi, and R. GonzalezMartinez, "On the role of non-basal deformation mechanisms for the ductility of Mg and Mg-Y alloys," Acta Materialia, vol. 59, no. 2, pp. 429-439, 2011.

[28] K. Hantzsche, J. Bohlen, J. Wendt, K. U. Kainer, S. B. Yi, and D. Letzig, "Effect of rare earth additions on microstructure and texture development of magnesium alloy sheets," Scripta Materialia, vol. 63, no. 7, pp. 725-730, 2010.

[29] T. L. Chia, M. A. Easton, S. M. Zhu, M. A. Gibson, N. Birbilis, and J. F. Nie, "The effect of alloy composition on the microstructure and tensile properties of binary Mg-rare earth alloys," Intermetallics, vol. 17, no. 7, pp. 481-490, 2009.

[30] Q. Zhang, T.-W. Fan, L. Fu, B.-Y. Tang, L.-M. Peng, and W.-J. Ding, "Ab-initio study of the effect of rare-earth elements on the stacking faults of Mg solid solutions," Intermetallics, vol. 29, pp. 21-26, 2012.

[31] J. Zhang, Y. C. Dou, G. B. Liu, and Z. X. Guo, "First-principles study of stacking fault energies in Mg-based binary alloys," Computational Materials Science, vol. 79, pp. 564-569, 2013.

[32] R. Pynn and G. L. Squires, "Measurements of the normal-mode frequencies of magnesium," Proceedings of the Royal Society of London. Series A, vol. 326, no. 1566, p. 347, 1972.

[33] G. Kresse and J. Hafner, "Ab initio molecular dynamics for open-shell transition metals," Physical Review B, vol. 48, no. 17, p. $13115,1993$.

[34] G. Kresse and J. Furthmller, "Efficiency of ab-initio total energy calculations for metals and semiconductors using a plane-wave basis set," Computational Materials Science, vol. 6, no. 1, pp. 1550, 1996.

[35] G. Kresse and J. Furthmüller, "Efficient iterative schemes for ab initio total-energy calculations using a plane-wave basis set," Physical Review B, vol. 54, no. 16, pp. 11169-11186, 1996.

[36] P. E. Blöchl, "Projector augmented-wave method," Physical Review B, vol. 50, no. 24, pp. 17953-17979, 1994.

[37] G. Kresse and D. Joubert, "From ultrasoft pseudopotentials to the projector augmented-wave method," Physical Review B, vol. 59, no. 3, pp. 1758-1775, 1999.

[38] J. P. Perdew, K. Burke, and M. Ernzerhof, "Generalized gradient approximation made simple," Physical Review Letters, vol. 77, no. 18, pp. 3865-3868, 1996.

[39] J. P. Perdew, K. Burke, and M. Ernzerhof, "Generalized gradient approximation made simple [Phys. Rev. Lett. 77, 3865 (1996)]," Physical Review Letters, vol. 78, no. 7, p. 1396, 1996.

[40] H. J. Monkhorst and J. D. Pack, "Special points for Brillouinzone integrations," Physical Review. B. Solid State, vol. 13, no. 12, pp. 5188-5192, 1976.

[41] N. W. Ashcroft and N. D. Mermin, Solid State Physics, Holt, Rinehart and Winston, New York, NY, USA, 1976.

[42] Y. Qi and R. K. Mishra, "Ab initio study of the effect of solute atoms on the stacking fault energy in aluminum," Physical Review B, vol. 75, no. 22, Article ID 224105, 2007.

[43] P. E. Blöchl, O. Jepsen, and O. K. Andersen, "Improved tetrahedron method for Brillouin-zone integrations," Physical Review $B$, vol. 49, pp. 16223-16233, 1994.

[44] G. Kresse, M. Marsman, and J. Furthmüller, "VASP the guide," http://www.vasp.at/.

[45] A. Togo, L. Chaput, I. Tanaka, and G. Hug, "First-principles phonon calculations of thermal expansion in $\mathrm{Ti}_{3} \mathrm{SiC}_{2}, \mathrm{Ti}_{3} \mathrm{AlC}_{2}$, and $\mathrm{Ti}_{3} \mathrm{GeC}_{2}$," Physical Review B, vol. 81, no. 17, Article ID 174301, 6 pages, 2010.

[46] A. Togo, F. Oba, and I. Tanaka, "First-principles calculations of the ferroelastic transition between rutile-type and $\mathrm{CaCl}_{2}$-type $\mathrm{SiO}_{2}$ at high pressures," Physical Review B, vol. 78, no. 13, Article ID 134106, 2008.

[47] A. Togo, Phonopy, http://phonopy.sourceforge.net/i.

[48] P. Vinet, J. H. Rose, J. Ferrante, and J. R. Smith, "Universal features of the equation of state of solids," Journal of Physics: Condensed Matter, vol. 1, no. 11, pp. 1941-1963, 1989.

[49] J. R. Rice, "Dislocation nucleation from a crack tip: an analysis based on the Peierls concept," Journal of the Mechanics and Physics of Solids, vol. 40, no. 2, pp. 239-271, 1992.

[50] N. Chetty and M. Weinert, "Stacking faults in magnesium," Physical Review B, vol. 56, no. 17, pp. 10844-10851, 1997. 
[51] L. Wen, P. Chen, Z.-F. Tong, B.-Y. Tang, L.-M. Peng, and W.J. Ding, "A systematic investigation of stacking faults in magnesium via first-principles calculation," The European Physical Journal B, vol. 72, no. 3, article 397, 2009.

[52] Q. Zhang, L. Fu, and T. W. Fan, "Abinitio study of the effect of solute atoms $\mathrm{Zn}$ and $\mathrm{Y}$ on stacking faults in Mg solid solution," Physica B: Condensed Matter, vol. 416, pp. 39-44, 2013.

[53] A. Datta, U. V. Waghmare, and U. Ramamurty, "Structure and stacking faults in layered $\mathrm{Mg}-\mathrm{Zn}-\mathrm{Y}$ alloys: a first-principles study," Acta Materialia, vol. 56, no. 11, pp. 2531-2539, 2008.

[54] J. A. Yasi, T. Nogaret, D. R. Trinkle, Y. Qi, L. G. Hector Jr., and W. A. Curtin, "Basal and prism dislocation cores in magnesium: comparison of first-principles and embedded-atom-potential methods predictions," Modelling and Simulation in Materials Science and Engineering, vol. 17, no. 5, Article ID 055012, 2009.

[55] T. W. Fan, B. Y. Tang, L. M. Peng, and W. Ding, "First-principles study of long-period stacking ordered-like multi-stacking fault structures in pure magnesium," Scripta Materialia, vol. 64, no. 10, pp. 942-945, 2011.

[56] Y. Wang, L.-Q. Chen, Z.-K. Liu, and S. N. Mathaudhu, "Firstprinciples calculations of twin-boundary and stacking-fault energies in magnesium," Scripta Materialia, vol. 62, no. 9, pp. 646-649, 2010.

[57] A. E. Smith, "Surface, interface and stacking fault energies of magnesium from first principles calculations," Surface Science, vol. 601, no. 24, pp. 5762-5765, 2007.

[58] A. Couret and D. Caillard, "An in situ study of prismatic glide in magnesium-II. Microscopic activation parameters," Acta Metallurgica, vol. 33, no. 8, pp. 1455-1462, 1985.

[59] R. L. Fleischer, "High-temperature, high-strength materialsan overview," JOM, vol. 37, no. 12, pp. 16-20, 1985.

[60] R. L. Fleischer, "Stacking fault energies of HCP metals," Scripta Metallurgica, vol. 20, no. 2, pp. 223-224, 1986.

[61] Y. T. Zhu, X. Z. Liao, and X. L. Wu, "Deformation twinning in nanocrystalline materials," Progress in Materials Science, vol. 57, no. 1, pp. 1-62, 2012. 

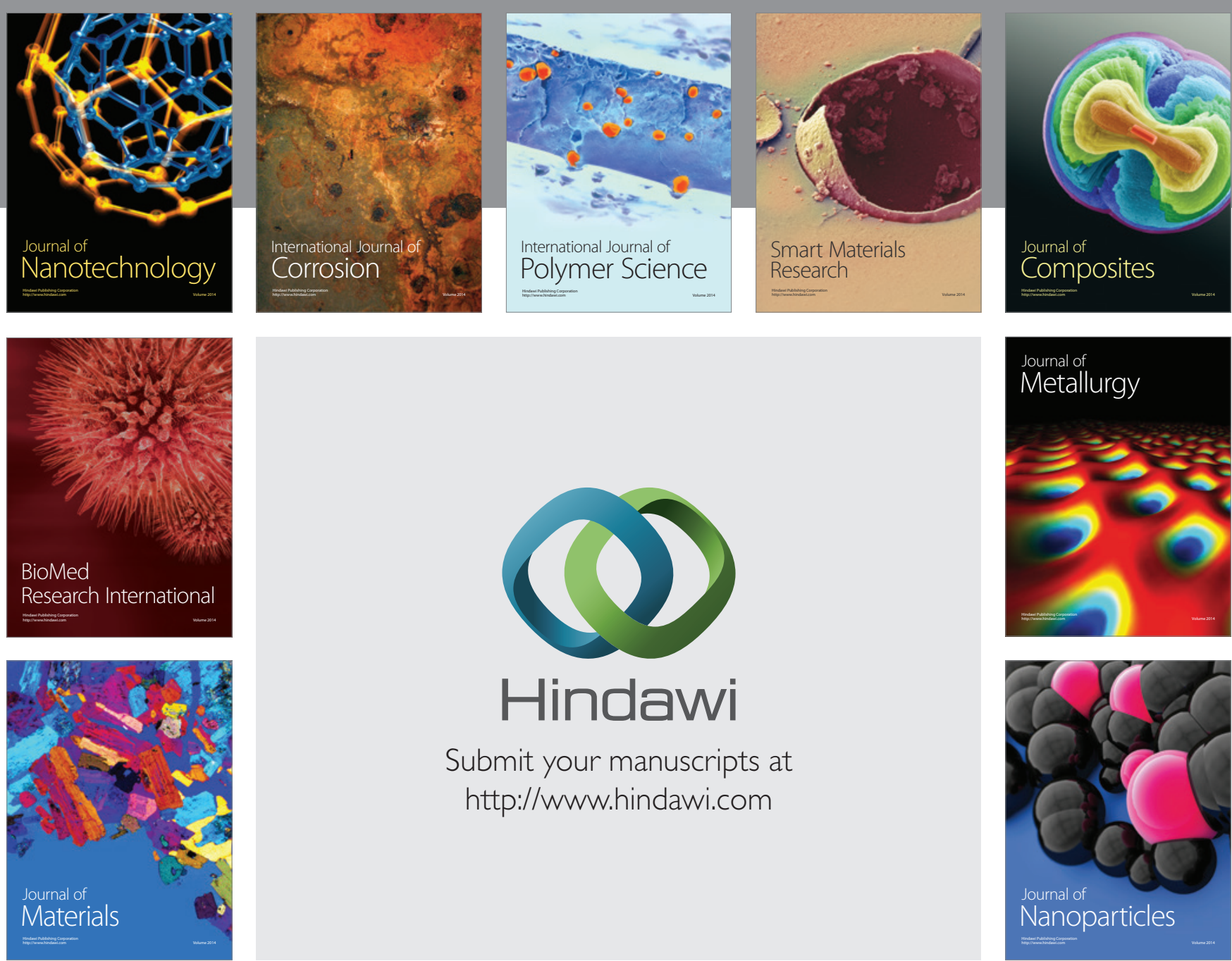

\section{Hindawi}

Submit your manuscripts at

http://www.hindawi.com

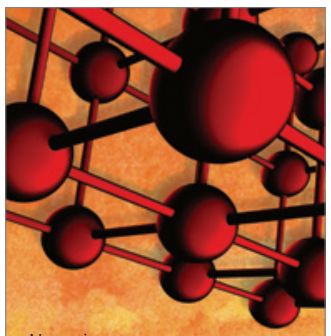

Materials Science and Engineering
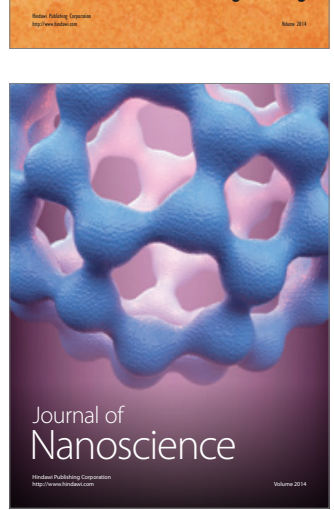
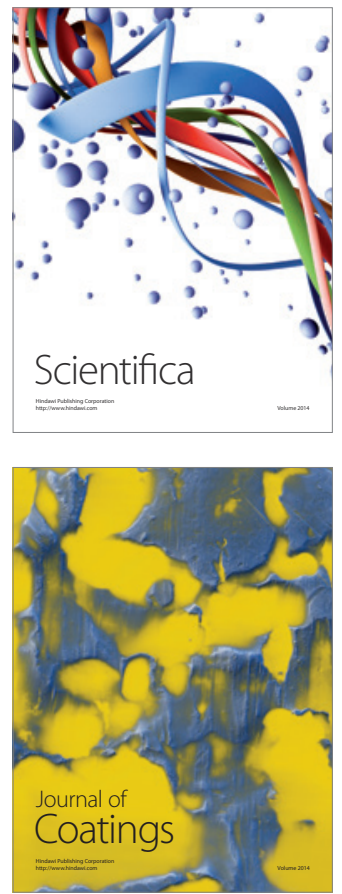
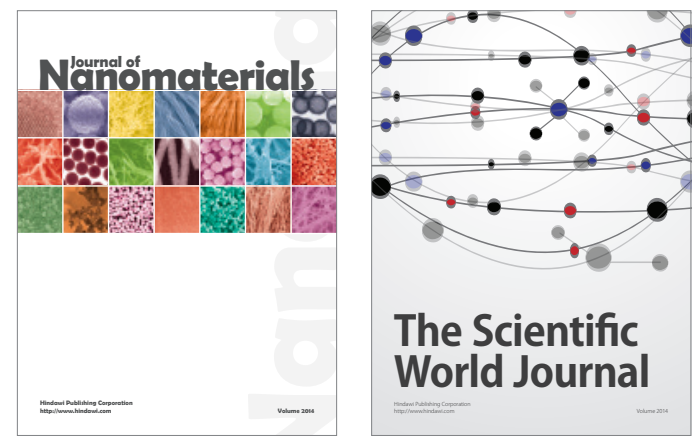

The Scientific World Journal
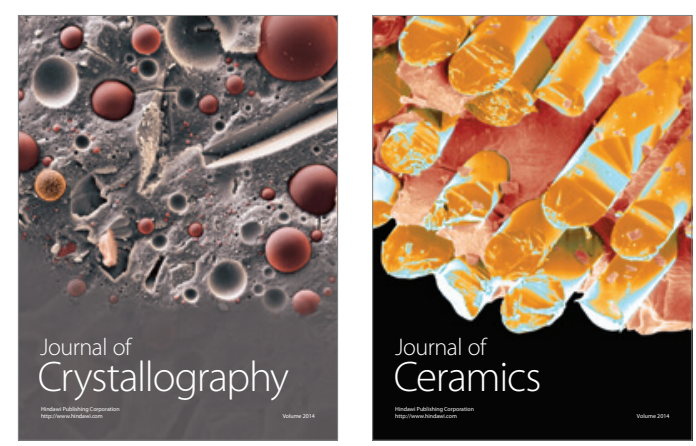
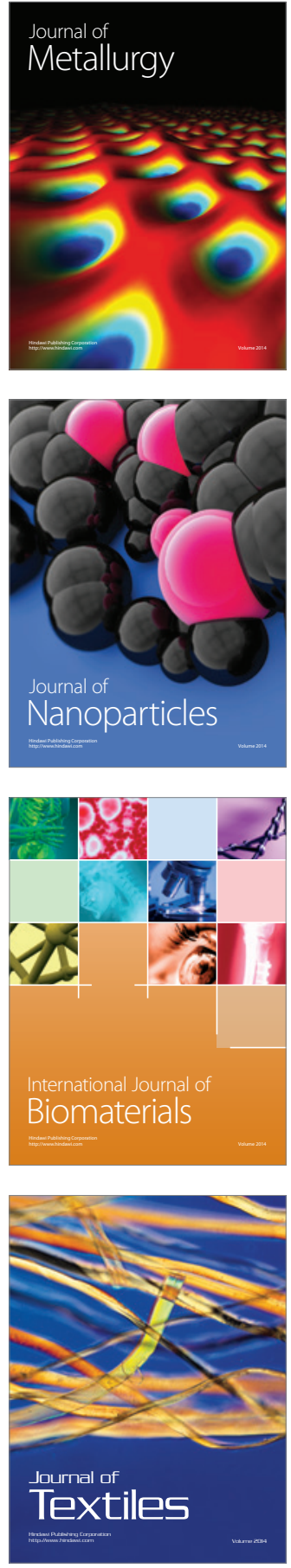